\title{
Article
}

\section{The Sustainable Development Goals: a plan for building a better world?}

Pogge, Thomas $\mathrm{W}$ and Sengupta, $\mathrm{M}$

Available at http://clok.uclan.ac.uk/15609/

Pogge, Thomas W and Sengupta, M (2015) The Sustainable Development Goals: a plan for building a better world? Journal of Global Ethics, 11 (1). pp. 56-64. ISSN 1744-9626

It is advisable to refer to the publisher's version if you intend to cite from the work. http://dx.doi.org/10.1080/17449626.2015.1010656

For more information about UCLan's research in this area go to http://www.uclan.ac.uk/researchgroups/ and search for < name of research Group>.

For information about Research generally at UCLan please go to http://www.uclan.ac.uk/research/

All outputs in CLoK are protected by Intellectual Property Rights law, including Copyright law. Copyright, IPR and Moral Rights for the works on this site are retained by the individual authors and/or other copyright owners. Terms and conditions for use of this material are defined in the policies page.

\section{CLoK}

Central Lancashire online Knowledge www.clok.uclan.ac.uk

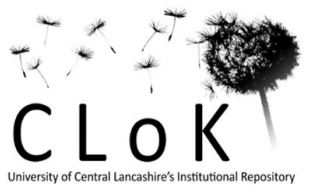




\title{
The Sustainable Development Goals: a Plan for Building a Better World?
}

\author{
Thomas Pogge and Mitu Sengupta
}

\begin{abstract}
Despite some clear positives, the draft text of the Sustainable Development Goals (SDGs) does not fulfill its self-proclaimed purpose of inspiring and guiding a concerted international effort to eradicate severe poverty everywhere in all its forms. We offer some critical comments on the proposed agreement and suggest ten ways to embolden the goals and amplify their appeal and moral power. While it may well be true that the world's poor are better off today than their predecessors were decades or centuries ago, to judge whether this is moral progress, we must bring into view what was possible then and what is possible now. We may well find that there have never been so many people avoidably subjected to life-threatening deprivations as there are today, and if this is the case, we should insist that our governments end this oppression immediately through appropriate institutional reforms to be prominently outlined in their post-2015 agenda.
\end{abstract}

Keywords: SDGs, MDGs, post-2015 agenda, poverty, inequality, sustainability.

\section{Author affiliations:}

Having received his PhD in philosophy from Harvard, Thomas Pogge is Leitner Professor of Philosophy and International Affairs and founding Director of the Global Justice Program at Yale. He holds part-time positions at King's College London and the Universities of Oslo and Central Lancashire. Pogge is a member of the Norwegian Academy of Science as well as President of Academics Stand Against Poverty (ASAP), an international network aiming to enhance the impact of scholars, teachers and students on global poverty, and of Incentives for Global Health, a team effort toward developing a complement to the pharmaceutical patent regime that would improve access to advanced medicines for the poor worldwide (www.healthimpactfund.org).

Mitu Sengupta is Associate Professor of Politics and Public Administration, Ryerson University, Toronto, Canada. Dr. Sengupta is the head of research and development for the Centre for Development and Human Rights (CDHR), a non-governmental organization based in New Delhi, India, and a director of Academics Stand Against Poverty (ASAP), an international network, founded at Yale University, that aims to leverage the resources of academia towards the end of eradicating global poverty. 
To be adopted in 2015 by the United Nations General Assembly (UNGA), the Sustainable Development Goals (SDGs) are meant to guide global development efforts over the subsequent 15 years. They replace the Millennium Development Goals (MDGs), which hold sway in the 2000-2015 period. In order to forge a widely acceptable formulation of the SDGs, the UNGA had instituted an Open Working Group. This OWG has recently completed its mandate by publishing a draft text with 17 goals and 169 targets that was placed before the UNGA in September 2014 and currently serves as the basis for intergovernmental negotiations in the 12 months thereafter (OWG 2014).

Like their predecessors, the SDGs will be a statement of aspirations: a voluntary agreement rather than a binding treaty. This is a drawback insofar as states may feel more tempted to skimp on their commitments. But it is also an opportunity insofar as states may be willing to adopt an agenda that is more ambitious in scope and vision when this agenda imposes on them no legally binding obligations. Drafting a common vision for 2030 can raise the gaze of politicians and officials beyond their usual preoccupations with short-term political advantage or narrowly defined national interest, can lead them to think imaginatively about that cosmopolis of the future whose foundations are now being shaped in this early stage of globalization.

In our assessment, the OWG draft misses this important opportunity. Despite some clear positives, the draft text of the SDGs does not fulfill its self-proclaimed purpose of inspiring and guiding a concerted international effort to eradicate severe poverty everywhere in all of its forms. Based on critical observations on the proposed agreement, we suggest ten ways to embolden the goals and amplify their appeal and moral power.

\section{To strengthen accountability in the post-2015 agenda, the new development goals should} contain specific references to whose goals they are supposed to be, clearly stipulating the responsibilities of competent agents.

Accountability is the key to effective development goals. While the SDGs are commendable for their inclusion of goal-specific means of implementation they fail to specify, for each proposed goal, whose goal it is supposed to be: who is supposed to do what to get it accomplished. Failing that, the proposed SDGs are, once again, a wish list only, with very little moral force. Take, for instance, the proposed target 5.1: "End all forms of discrimination against all women and girls everywhere." At whom is this instruction directed? What efforts does it require from states acting domestically, from states acting beyond their own borders, from international agencies, from multinational enterprises? Without any hint of an answer to these questions, the most influential agents, who are generally best placed to advance the objective, will also be best able to divert attention away from their own responsibilities. The poorest countries might be blamed for failing 
sufficiently to reduce their huge hunger problems, while upper-middle-income countries can rest easy with eradicating the tiny last remnants of undernourishment. This is precisely what happened with the MDGs, where the poorest countries got the blame for not reducing their huge deprivation rates fast enough. If repeated, this deficiency stands to undermine the moral authority and success of the new agenda.

2. To achieve sustainable development, the SDGs should not merely appeal for greater efforts by governments and other powerful agents but should also call for structural reforms of the global institutional order that conditions the options and incentives of these and other agents.

While official and non-governmental development assistance certainly affects the evolution of global poverty and income inequality, it is not nearly sufficient to balance the centrifugal tendencies produced by the ordinary operation of the world economy as presently structured. The OWG draft misses a crucial opportunity to question and reform such unjust arrangements. There are only a few passing references to institutional reforms that could diminish the headwinds blowing against the poor, although such reforms are crucial for the achievement of every goal on the agenda. For example, the draft says precious little about illicit financial flows, which are known to aggravate oppression and poverty worldwide and dwarf the flow of international development assistance. ${ }^{1}$ The initial version of the OWG draft included a stand-alone target for global cooperation to reduce international tax dodging; but this target was drastically cut back in the final revision of the draft, which piously calls (on whom?) for reducing "illicit financial and arms flows" (target 16.4) and asks for cooperation toward improving poor countries' capacity for tax and revenue collection (target 17.1). If we are serious about tackling the scourge of illicit financial flows, we should insist on stand-alone targets that name responsible agents and specify their tasks. In particular, we should call on governments to mandate (i) disclosure of the ultimate beneficial owners of companies and of the controlling parties of trusts and foundations, (ii) public country-by-country reporting of profits and other tax-relevant information by multinational enterprises, (iii) automatic exchange of tax-relevant financial information by national tax authorities worldwide, (iv) public reporting on funds paid to governments for the extraction of natural resources and on the use of those funds and (v) tough sanctions, including jail time, for professionals who facilitate illicit financial flows, for instance senior officers from global banks, accounting firms, law firms, insurance companies and hedge funds. In addition, we should call on governments to commit to (vi) harmonizing anti-money laundering regulations internationally and (vii) carrying out clear, reliable, frequent and

\footnotetext{
${ }^{1}$ For further information and additional literature, see www.yale.edu/macmillan/globaljustice/DirtyMoney.html (last accessed December 26, 2014).
} 
timely public fiscal reporting as well as opening up their fiscal policy-making process to public participation. ${ }^{2}$

3. To enlarge its ambition and impact, the new agenda should include strong human rights language.

The new agenda does not aim high enough in recognizing, protecting, and fulfilling human rights, taking into consideration their universality, indivisibility, and interdependence. For example, going against the aspirations of women's groups worldwide, the gender equality goal does not recognize the human rights of women and girls. Food, water, and sanitation are also not framed as human rights. Furthermore, rather than demand universal social protection floors, proposed target 1.3 calls for "nationally appropriate social protection systems and measures for all, including floors." It is perhaps understandable that strong human rights language and a universal or zero target approach for all minimum core economic and social rights obligations have been carefully avoided in the formulation of the new goals. Developing countries have fought hard for the inclusion of nationally determinable targets and language on respecting national policy space (target 17.15), fearing that they will not be able to meet the burden of 'zero goals,' which may then be used to name, shame and blame them. While this is a legitimate concern, the solution is not to dilute the SDGs by aiming for whatever is readily feasible with national resources, but to specify what wealthy countries and enterprises must do to reduce impediments and to increase assistance so that ambitious targets can be met even in the poorest countries.

4. To ensure that progress toward the goals is honestly measured, definitions and measurement methods must be locked in for the 15-year period rather than be allowed to be revised with hindsight and the tracking of progress must be entrusted to an international group of independent high-level experts rather than to politically exposed agencies such as the World Bank and the UN Food and Agriculture Organization (FAO).

The new agenda will be worth very little without reliable measures of progress toward the agreed objectives. While poverty may indeed have declined in the last 25 years, the trend depends heavily on the definitions and measurement methods used. For example, the World Bank has defined poverty ever more narrowly by replacing the original purchasing power parity threshold of $\$ 1.00$ per person per day in 1985 US-dollars (as referenced in the UN Millennium Declaration and in MDG-1) with a lower \$1.08 per person per day in 1993

\footnotetext{
2 These were among the leading demands that emerged from a crowd-funded Delphi study that ASAP completed with a panel of 26 leading experts. See http://academicsstand.org/2014/09/policy-options-foraddressing-illicit-financial-flows-results-from-a-delphi-study (last accessed December 26, 2014).
} 
US-dollars and then with an even lower $\$ 1.25$ person per day in 2005 US-dollars. This has led to a much prettier poverty trend: the World Bank reports that, in the developing world, the percentage of people living in poverty has declined from $42.95 \%$ in 1987 to $19.15 \%$ in 2010. This narrowing of the definition of poverty has also led to massive undercounting of those who cannot meet their basic needs (Pogge 2010, 63-68; 2013). Were the World Bank using a more reasonable poverty line of $\$ 3$ per person per day in 2005 US-dollars, it would report that the number of poor has risen from 3237.29 million in 1987 to 3263.89 million in 2010 (FAO 2012, 50).

Likewise, the FAO has recently transformed a steadily rising undernourishment trend into a steadily falling one by introducing an "improved methodology" that counts as undernourished only those whose caloric intake is "inadequate to cover even minimum needs for a sedentary lifestyle" for "over a year" (FAO 2012, 50). This definition unreasonably excludes those who suffer other nutritional deficits (in proteins, vitamins, minerals and other micronutrients) or are not adequately nourished by the sedentary diet because they must do serious physical work in their home or for a living. Midway methodological revisions divert efforts toward merely cosmetic progress and undermine the credibility and moral authority of the SDGs.

\section{Recommendations for improving specific goals}

\section{To realize the full potential of SDG-1, "End poverty in all its forms everywhere," the goal} must include measures of poverty other than the income-based measure of \$1.25 per day and must specify systemic global reforms that would reliably end poverty.

There is a welcome shift in the proposed agenda's flagship poverty goal from the MDG language of reduction to that of eradication. However, no measure of poverty, other than the money-metric one of $\$ 1.25$ per day (2005 purchasing power), is mentioned, even though this income-based measure fails to capture many of the hardships that constitute poverty in the real world, such as child labor, chronic undernourishment, illiteracy, exposure to violence and lack of access to safe drinking water, shelter, sanitation, electricity and essential medicines. This contradicts the language of ending poverty "in all its forms everywhere" in the goal's title. Such ambitious language is also undermined by the means of implementation associated with this goal, which make no reference to the structural reforms required to tackle the root causes of poverty. Cancelling the external debt of Highly Indebted Poor Countries and closing down opportunities for tax dodging are examples of structural reforms that could be framed as means of implementation for this goal. 


\section{To strengthen proposed SDG-5, "Achieve gender equality and empower all women and girls," there should be explicit reference, at the target level, to ending all forms of discrimination on the basis of sexual orientation, gender identity or gender expression.}

Like the inequality goal, the inclusion of a stand-alone goal on gender equality and empowerment of women and girls did not come without a struggle; there was stiff opposition from conservative governments and civil society groups. While the goal could certainly be stronger, it is a significant achievement that proposed SDG-5 comes with five commendable targets on ending discrimination against women and girls, eliminating violence against women and girls, eliminating harmful practices such as early and forced marriage, recognizing and valuing domestic work, and ensuring universal access to sexual and reproductive rights (rather than only sexual and reproductive health). The OWG has also tried to integrate gender equality and women's empowerment objectives into a number of the other goals, such as that on education, where target 4.7 calls for education for gender equality. In order to ensure advances in these dimensions, proper monitoring and tracking is crucial. As it is, we know far too little about gender-related discrimination and disadvantage because currently gathered survey data tend to focus on entire households (thereby systematically blocking our inequities within households) and also tend to neglect the distinctive significance some dimensions of deprivation have for women and girls. ${ }^{3}$

Given the otherwise progressive tenor of SDG-5 and its associated targets - and the attempt to recognize gender equality as a multidimensional concept - it is a glaring omission that there is no language whatsoever in the OWG's text on ending discrimination, violence, and denials of sexual and reproductive rights on the basis of a person's sexual orientation, gender identity, or gender expression. Ending such gender-based discrimination should be recognized as a core human rights goal that is crucial to achieving sustainable development. Because of their real or perceived sexual orientation, gender identity or gender expression, many people are not only bullied, beaten, raped, and murdered, they are marginalized, isolated, and denied access to education, employment, healthcare, housing, social assistance, and community resources. Sadly, even in 2015, ending discrimination on the basis of sexual orientation and gender identity remains a politically sensitive issue. If we are serious about attaining sustainable development for all human beings, about leaving no-one behind, and about raising the gaze of the world through the SDGs, it is one on which we must not compromise.

\footnotetext{
${ }^{3}$ The recently proposed Individual Deprivation Measure is the outcome of a deliberate effort to overcome these limitations. See Wisor et al. 2014.
} 
7. To increase the impact of the proposed SDG-10, "Reduce inequality within and among countries," the first target, 10.1, should specify by how much the growth of the bottom $40 \%$ should exceed the national average. Here a suitable target would be to halve, by 2030, each country's logarithmic distance from a Palma ratio of $1 .{ }^{4}$ In addition, there should be references to inequality reduction in the targets of other goals. Indicators used to monitor targets should be disaggregated by relevant categories such as gender, race, ethnicity, religion and geographical area. In keeping with the principle of "leave no one behind," widely endorsed in global consultations on the post-2015 agenda, no target should be considered achieved until it has been met for all relevant segments of a population. ${ }^{5}$

We welcome the inclusion of a stand-alone goal on inequality reduction, which civil society and developing countries have fought long and hard for. ${ }^{6}$ Proposed SDG-10 is vital to the success of the post-2015 agenda, and it must not be cut from the framework's final draft, nor be submerged under some other goal, such as poverty eradication or economic growth. While the conventional prescription against poverty is economic growth, overcoming existing deprivations through global growth (leaving inequalities as they are or even allowing them to worsen, as they did in the period since the end of the Cold War) would take far too long - at $2 \%$ real growth, the poorer half would take 35 years to double its real income - and would also impose unsustainable environmental burdens as the richer half would then also double its 30-times-larger income and consumption during the same period. Furthermore, so long as the poorer half of humanity have only $3.3 \%$ of global income and an even smaller share of global wealth, as well as greatly inferior education, health care and civil rights protection, it is very difficult for them to become full agents in their own emancipation. They will be sustainably liberated from deprivation only if they can fully participate in this liberation and defend it in the political realm. In this way, the achievement of all development goals depends on an empowerment of the poor by reducing excessive social, economic and civil rights inequalities. An explicit commitment

\footnotetext{
${ }^{4}$ The Palma ratio is the income share of the richest $10 \%$ divided by that of the poorest $40 \%$. We propose that each country should aim, by 2030, to reduce income inequality to the square root of its present Palma ratio. Thus, countries with current Palma ratios of 4, 2.25 and 1.69 would commit to reaching, by 2030, Palma ratios of 2, 1.5 and 1.3, respectively. Countries with current Palma ratios of 1 or below would merely need to remain within this range. See www.cgdev.org/sites/default/files/it-all-about-tails-palma-measure-income-inequality.pdf (last accessed December 26, 2014) for a discussion and defense of the Palma ratio. For some data from European countries, see Cingano 2014, Table A1.2, p. 36.

5 "The indicators that track them [the suggested targets] should be disaggregated to ensure no one is left behind and targets should only be considered 'achieved' if they are met for all relevant income and social groups" (HLP 2014, ix).

${ }^{6}$ See Third World Network, "SDGs: The disappearing act of the 'inequality" goal,'" www.twn.my/title2/unsd/2014/unsd140602.htm (last accessed December 26, 2014).
} 
to eradicating inequality among nations, moreover, will ensure that the post-2015 agenda is genuinely universal. In its absence, the language of universalism will be treated cynically, as a mask for real inequalities, thus undermining the moral authority of the new goals.

8. To strengthen proposed SDG-13, "Take urgent action to combat climate change and its impacts," there should be one or more targets discouraging and aiming to terminate the ecologically most damaging modes of production and consumption.

The starring role given to the word "sustainable" gives the challenge of climate change a much-deserved central place, which is also confirmed by it getting a stand-alone goal. Once again, however, the moral power of this goal will depend on the strength of its targets and the effectiveness of its means of implementation. The targets for SDG-13 are conspicuously weak. For one thing, they include no concrete commitment to combat climate change itself (mitigation) after an important target on investing in low-carbon solutions, which had appeared in earlier OWG drafts, was dropped from the final version. Not even one target is devoted to discouraging or ending the ecologically most damaging modes of production and consumption, such as coal-fired power plants without carbon sequestration, fracking, beef consumption and the tax-exemption of frequent flyer miles. It is fine, of course, to reiterate the UN Framework Convention on Climate Change commitment to "mobilizing jointly USD100 billion annually by 2020 from all sources to address the needs of developing countries in the context of meaningful mitigation actions." But why not add here that these funds should be raised in a way that discourages the burning of fossil fuels, for example through a global fee on excessive greenhouse gas (GHG) emissions? Each country would have to pay a fee (starting at \$2 per ton in 2016 and then rising by $\$ 2$ annually) for each ton of $\mathrm{CO}_{2}$ equivalent above a certain threshold (4 tons per capita in 2016 and gradually declining thereafter). This fee would comfortably raise the promised $\$ 100$ billion by 2020 and it would also increase the price of fossil-fuel based consumption, thereby encouraging both conservation and the development of cleaner energy alternatives (wind, solar, nuclear, etc.). The adaptation targets included under SDG13 betray a technocratic approach to climate change, with only slightest token efforts to connect this goal to other SDG objectives. Neither contradictions (with goals such as industrialization and economic growth) nor complementarities (with goals such as poverty eradication and inequality reduction) are sufficiently recognized.

\section{To strengthen SDG-16, "Promote peaceful and inclusive societies for sustainable} development, provide access to justice for all and build effective, accountable and inclusive institutions at all levels," concrete responsibilities must be specified for the 


\section{affluent countries, particularly in relation to the core target (16.1) of reducing all forms of violence.}

Being exposed to violence in one's own household and daily life is a prominent and pervasive part of what it means to be poor. Such violence reflects governance failures endemic in developing countries: predatory elites who do not care about their poor compatriots and even profit by driving them off their land or coercing them into exploitative conditions as factory workers, day laborers, domestic servants or sex workers. Small-scale violence and the continual threat thereof - just like the large-scale violence of wars, civil wars and local insurrections - is a terrible burden upon the poor and a grave impediment to efforts to improve their lives. The Sustainable Development Goals must recognize and suitably highlight this reality.

Both SDG drafts have recognized the importance of violence by assigning it a separate goal: Goal 11 in the draft by the High-Level Panel and Goal 16 in the OWG draft. But both drafts fall short by proposing that government should simply agree to specified reductions: "reduce violent deaths per 100,000 by $x$ and eliminate all forms of violence against children" (HLP 11.1); "significantly reduce all forms of violence and related death rates everywhere" (OWG 16.1). Such formulations express mere wishes, which are easy to endorse because they require no commitment. For such wishes to come true, they must be converted into genuine goals through a clear assignment of responsibilities to specific competent actors. A goal requires an agent or agents whose goal it is and who takes responsibility for its achievement.

One may reply that the assignment of responsibilities is implicit: each country must achieve the required reduction within its own national territory. But as we have seen, this would be a morally implausible and politically ineffective assignment. It gives the poorest countries the largest tasks; and it completely overlooks how violence and corruption in developing societies are incentivized and facilitated by foreign factors over which members of this society have no control. One example is the international arms trade which greatly amplifies violence in the developing world. To curb this trade, the world's arms exporting countries must shoulder key responsibilities: to accept constraints on whom they sell arms to, to accept substantial penalties when weapons they sold fall into the wrong hands and to accept a tax on all arm sales both to discourage them and to raise revenues for an international fund to mitigate violence and its effects.

Another example is the might-makes-right principle governing international loans and resource sales (Pogge 2001). Other countries should not recognize persons or groups, merely because they hold effective power in a developing country, as entitled to borrow in the name of this country and to effect legally valid sales of its natural resources. Doing so promotes the survival of repressive regimes that lack domestic legitimacy and impoverishes the country's people who, without their consent, are saddled with repayment obligations and robbed of their natural resources. In addition, powerful incentives are provided to 
generals and rebel groups to take over the state or to demand pay-offs for not attempting to do so.

The means of implementation associated with SDG-16 should explicitly recognize such global drivers of conflict, and spell out what affluent countries and other powerful international agents (such as transnational corporations) need to do to curb them. Doing so will ease the concern, expressed by many developing countries, that the inclusion of a "peace" goal in the SDGs is reserved for developing countries alone, and that it will be used merely to impose new conditionalities on the recipients of international aid.

\section{To give meaning to SDG-17, "Strengthen the means of implementation and revitalize the global partnership for sustainable development," concrete responsibilities must be specified for the affluent countries and international agencies.}

The new global partnership goal proposed by the OWG, SDG-17, is intended to be a more robust version of the paltry MDG-8, the only MDG that deals directly with the responsibilities of affluent states and international agencies. The absence of measurable targets, indicators, and achieve-by dates for MDG-8 indicates that the MDGs were not founded on a 'global partnership' at all, but were essentially a slate of instructions for the developing countries alone. SDG-17 is certainly more comprehensive than MDG-8, containing 19 targets on issues such as finance, technology, trade, data monitoring and accountability. Nonetheless, the key defect of MDG-8 also mars SDG-17. It seems that, once again, the world's most powerful agents - affluent states, international organizations, multinational enterprises - will be shielded from any concrete responsibilities for achieving the SDGs when, given their wealth and influence, they ought to be taking the lead in providing the needed resources and in implementing systemic institutional reforms that will address the root causes of poverty. These needed reforms include changing the rules that encourage illicit financial outflows from developing countries or force the poorest countries to pay interest on debts accumulated by previous corrupt and often unelected leaders. Instead, we are treated to rather banal language on the need for "multi-stakeholder partnerships" with private actors and civil society. If SDG-17 fails to hold the world's most influential agents sufficiently accountable for what they owe toward making sustainable development work, the concepts of partnership and universalism will remain a smokescreen for extreme global inequalities, thus weakening confidence in the goals.

A strong global partnership goal is essential for maintaining the moral authority of the post-2015 agenda as a whole. The targets for SDG-17 should be re-written to specify the concrete responsibilities of the affluent states in regard to implementing needed global institutional reforms and financing sustainable development. Responsibilities of these two kinds can often be discharged through a single institutional mechanism. For example, 
to deter and offset the effects of protectionist barriers - which distort trade and diminish trading opportunities for poor populations - rich countries providing subsidies or export credits might commit to paying a share of the value of such subventions into a Human Development Fund. ${ }^{7}$

\section{Concluding Thought}

There is much self-satisfaction in the official attitudes to the MDG and SDG exercises. Ban Ki Moon's words are typical: "Between 2000 and 2010, an estimated 3.3 million deaths from malaria were averted, and 22 million lives were saved from fighting tuberculosis. Access to antiretroviral therapy (ART) for HIV-infected people has saved 6.6 million lives since 1995. At the same time, gender parity in primary school enrolment, access to child and maternal health care, and in women's political participation improved steadily" (Ban 2014, 6). The world's governments imagine that they are doing something truly wonderful by making progress against deprivation, continuously improving the world to make it better than that of our parents and grandparents.

This self-image invokes a comparison with a fictional alternative history in which human lives would not have been improved through development efforts by UN agencies, foreign aid agencies, the Gates Foundation, the Global Fund, the President's Emergency Plan for AIDS Relief (PEPFAR), and the like. But this is altogether the wrong comparison. The world's governments should compare the world as it is with the world as they are required to shape it: a world so structured that human rights can be fully realized in it. $^{8}$ Given existing economic, technological and administrative capacities, the demand for such an international order is not especially ambitious. Achieving it would require minor institutional reforms that would raise the income share of humanity's poorer half from 4 to 6 percent - reforms that could have been implemented decades ago. Such a world would still have huge economic inequalities, but would have averted the life-threatening poverty that still blights the lives of half the human population along with the 180 million deaths from poverty-related causes, including some 50 million from malaria, tuberculosis and HIV/AIDS, in the decade of which Ban Ki Moon is so proud.

It may well be true that the world's poor are better off today than their predecessors were decades or centuries ago. But to judge whether this is moral progress, we must bring into view what was possible then and what is possible now. Taking this into account, we may

\footnotetext{
${ }^{7}$ This share might be 2 percent in 2016 and then increase by another 2 percent each year, reaching 30 percent in 2030. At today's level of subsidies and export credits, this mechanism would raise between $\$ 6$ billion (2016) and $\$ 90$ billion (2030) a year over the SDG period. For comparison, current official development assistance stands at ca. $\$ 130$ billion from all countries.

${ }^{8}$ Article 28, Universal Declaration of Human Rights.
} 
well find that there have never been so many people avoidably subjected to life-threatening deprivations as there are today: to lack of adequate nutrition, safe water, sanitation, shelter, clothing, education or medical care. In any case, our response to the fact that the situation of the world's poor is less oppressive in 2015 than it was in 1990 should be the same as any reasonable person's response to the fact that the situation of U.S. slaves was less oppressive in 1840 than in 1815: we should insist that our governments end this oppression immediately through appropriate institutional reforms.

\section{Bibliography}

Ban, Ki Moon (2014). "The Road to Dignity by 2030: Ending Poverty, Transforming All Lives and Protecting the Planet." Synthesis Report of the Secretary-General on the Post-2015 Agenda. New York, United Nations. Available at www.un.org/disabilities/documents/reports/SG_Synthesis_Report_Road_to_Dignity_by_2030.pdf (last accessed December 24, 2014).

Cingano, Frederico (2014). "Trends in Income Inequality and Its Impact on Economic Growth." OECD Social, Employment and Migration Working Papers, No. 163, OECD Publishing. Available at http://dx.doi.org/10.1787/5jxrjncwxv6j-en (last accessed December 28, 2014).

FAO (UN Food and Agriculture Organization) (2012). The State of Food Insecurity in the World 2012. Rome, FAO.

HLP (High-Level Panel of Eminent Persons on the Post-2015 Development Agenda) (2014). "A New Global Partnership: Eradicate Poverty and Transform Economies through Sustainable Development." Available at www.un.org/sg/management/pdf/HLP_P2015_Report.pdf (last accessed December 28, 2014.

OWG (Open Working Group) (2014). "Proposal for Sustainable Development Goals," issued by the UN as document A/68/970. Available at http://undocs.org/A/68/970 (last accessed December 24, 2014).

Pogge, Thomas (2001). "Achieving Democracy," in Ethics and International Affairs 15, pp. 3-23.

Pogge, Thomas (2010). Politics as Usual: What Lies behind the Pro-Poor Rhetoric. Cambridge, Polity Press.

Pogge, Thomas (2013). "Poverty, Hunger and Cosmetic Progress," in Malcolm Langford, Andy Sumner and Alicia Ely Yamin (eds.), The Millennium Development Goals and Human Rights: Past, Present and Future. Cambridge, Cambridge University Press, pp. 209-231.

Wisor, Scott, Sharon Bessell, Fatima Castillo, Joanne Crawford, Kieran Donaghue, Janet Hunt, Alison Jaggar, Amy Liu and Thomas Pogge (2014). The Individual Deprivation Measure: A Gender-Sensitive Approach to Poverty Measurement. Melbourne, The International Women's Development Agency. Available at www.iwda.org.au/research/individual-deprivation-measure (last accessed December 25, 2014). 